\title{
An assessment of green practices in Small and Medium-sized Enterprises (SMEs) using Graph- Theoretic Matrix Approach
}

\author{
Manoj Kumar Singh*, Pravin Kumar** and Saurabh Agrawal*** \\ * Department of Mechanical Engineering, Pusa Institute of Technology, Delhi, India \\ ** Department of Mechanical Engineering, Delhi Technological University, Delhi, India \\ *** Delhi School of Management, Delhi Technological University, Delhi, India \\ *Corresponding Author : manojsinghavp13@gmail.com
}

\begin{abstract}
The main purpose of the paper is to evaluate the green practices in Small and Medium Enterprises (SMEs). The growth and sustainability-related issues are equally important for SMEs as well as for multinational companies. Multinational companies have sufficient exposure to the international norms of environmental management and they are bound to follow them. Due to ignorance attitude and lack of information and resources, SMEs are less interested in green manufacturing. Thus, the assessment of the green practices of SMEs becomes very important in the present context. In this study, some of the major factors related to green manufacturing have been identified through the literature review. The green index is produced using the permanent matrix of all the factors using the Graph Theory Matrix Approach. It may be used to compare the green performance of one SME with another.
\end{abstract}

Keywords: Graph-theoretic matrix approach; Green manufacturing; permanent of a matrix; Green practices.

\section{INTRODUCTION}

Most of the attention towards green manufacturing/environmental concerns is focused on the large organizations/ original equipment manufacturers (OEMs). In India, a large number of small and medium enterprises (SMEs) are engaged in auto components manufacturing, and they are supplying the auto components to the local as well as multinational automobile manufacturers.

SMEs represent more than $90 \%$ of the manufacturing organizations in number and play a critical role in this endeavour (Rekik and Bergeron, 2017). Green practices in SMEs need to be integrated with all the processes to improve the environmental conditions and save scarce natural resources. Despite the availability of many research works on the role of large firms in environmental degradation, the role of SMEs remains relatively underexposed and unexplored (Perrini, 2006). The large manufacturing firms have a strategic relationship with multiple vendors as SMEs and most of the components/parts except the components of strategic importance are sourced from them. The negligence of implementation of green manufacturing practices in SMEs cannot be justified as SMEs are producing approximately two-third of the total pollution (Aragón-Correa et al. 2008). Generally, the policies are decided based on the insights from large firms and it is assumed that SMEs will force the customized/small version of the large firms' policies. This may be a misunderstanding of the policymakers (Aragón Correa et al. 2008).

Nowadays, the manufacturing industry is under pressure to implement stringent environmental regulations. 
Conservation of natural resources and environmental protection are considered major issues in the manufacturing sector. Circular economy and cleaner production have attracted many researchers and practitioners for their valuable contributions in these areas of research. Increasing the environmental awareness of the consumers is the main driving force that forces manufacturers to adopt green manufacturing practices. Some of the drivers and barriers of implementing green manufacturing practices in SMEs differ from those for large enterprises since SMEs are facing a lack of data, scarcity of resources, lack of technical expertise, and lack of experience, etc. for implementation of green initiatives (Ghazilla et al. 2015). Very few studies are available on the identification of factors influencing the implementation of green practices in Indian SMEs. Most of the studies in this field are inappropriate in actual practice. The main objectives of the study are given below:

- To highlight the need for the implementation of green practices in SMEs.

- To explore the factors influencing green practices in SMEs.

- To propose a framework to measure the level of implementation of green practices in an SME which may be used to compare with other similar SMEs

The rest of the paper has been arranged as: Section 2 presents the literature review of the factors influencing the green practices in Indian SME's. Section 3 presents the methodology of the Graph Theory Matrix Approach (GMTA). Section 4 presents the case illustration. Section 5 concludes the research work.

\section{LITERATURE REVIEW}

The external pressures such as the Govt. regulations, stakeholders, competitors, etc. are increasingly forcing organizations to implement the Environmental Management Systems (EMS) into their business processes (GonzalezBenito and Gonzalez Benito, 2006). In this respect, some of the valuable articles analyzing the determinant and their impacts on the development of green initiatives in supply chains have been observed (Zailani et al., 2012; Wu et al., 2012; Diabat and Govindan, 2011). The top management can make a strategy to implement the green supply chain practices proactively. It is a general understanding of the management that green management is only in compliance with the regulations. It is a general understanding of the management that green management is only needed to comply with the regulations while evaluating the environmental and economic performance (Walley and Whitehead, 1994). Zhu et al. (2007) also found that the green Supply Chain Management (GSCM) in China has only slightly improved environmental and operational performance. Molina-Azorı'n et al. (2009) observed that most studies have advocated green manufacturing practices for enhancing organizational performance. Aleisa and Alshayji (2019) stressed on utilization of wastewater. Haque et al. (2019) studied the characteristics of recycled concrete materials. Nasrollahi et al. (2019) worked on glycyrrhiza green supply network design.

\section{SOME OF THE MAJOR FACTORS OF GREEN PRACTICES}

In general, the management of SMEs is reluctant to follow the green practices due to capacity and resource constraints, a small level of manufacturing activities, and the involvement of a relatively small size of the workforce. They are also reluctant to implement the Govt. legislation and environmental regulations. But due to the external pressure and competitive advantages of green practices, SMEs are forced to implement environmental management systems (EMS). Some of the factors, such as customers' awareness towards the green products, effective implementation of the Govt. legislation, top management commitment, including some more factors as discussed in detail in the following subsections and summarised in Figure 1.

Top Management Commitment: Top management commitment refers to management's willingness to dedicate to green philosophy and collaborates with departments to adopt green practices (Olugu and Wong, 2011; Zailani et al., 2015). Dubey et al. (2017) worked on the belief of top management in achieving green manufacturing practices through 
reconfigurable manufacturing systems. They can influence the policy, planning, support for the green initiatives to be taken across the organization. Top management is the backbone of the planning and provides continuous support for green supply chain management in the strategic and action plans (Ravi \& Shankar, 2005).

Effective Govt. legislation and implementation: The government regulation and its implementation may encourage or discourage the innovation of the organization by imposing certain terms and conditions on the industry (Scupola, 2003). Environmental legislation and regulations are concerned with the sets of laws for the protection of the natural environment and the health of the employee and communities, which are to be implemented forcibly (Zakuan et al., 2012).

Economic Interest: According to Ravi and Shankar (2005), lack of funding for environmental projects and high prices of green products have proven to be the main financial barriers. Historically, the cost has been treated as one of the major performance measures. AlKhidir and Zailani (2009) observed that a high investment is required initially for the technology concerned with green design, green manufacturing, and green packaging. For engaging the environmental management, both direct and indirect costs are a significant barrier.

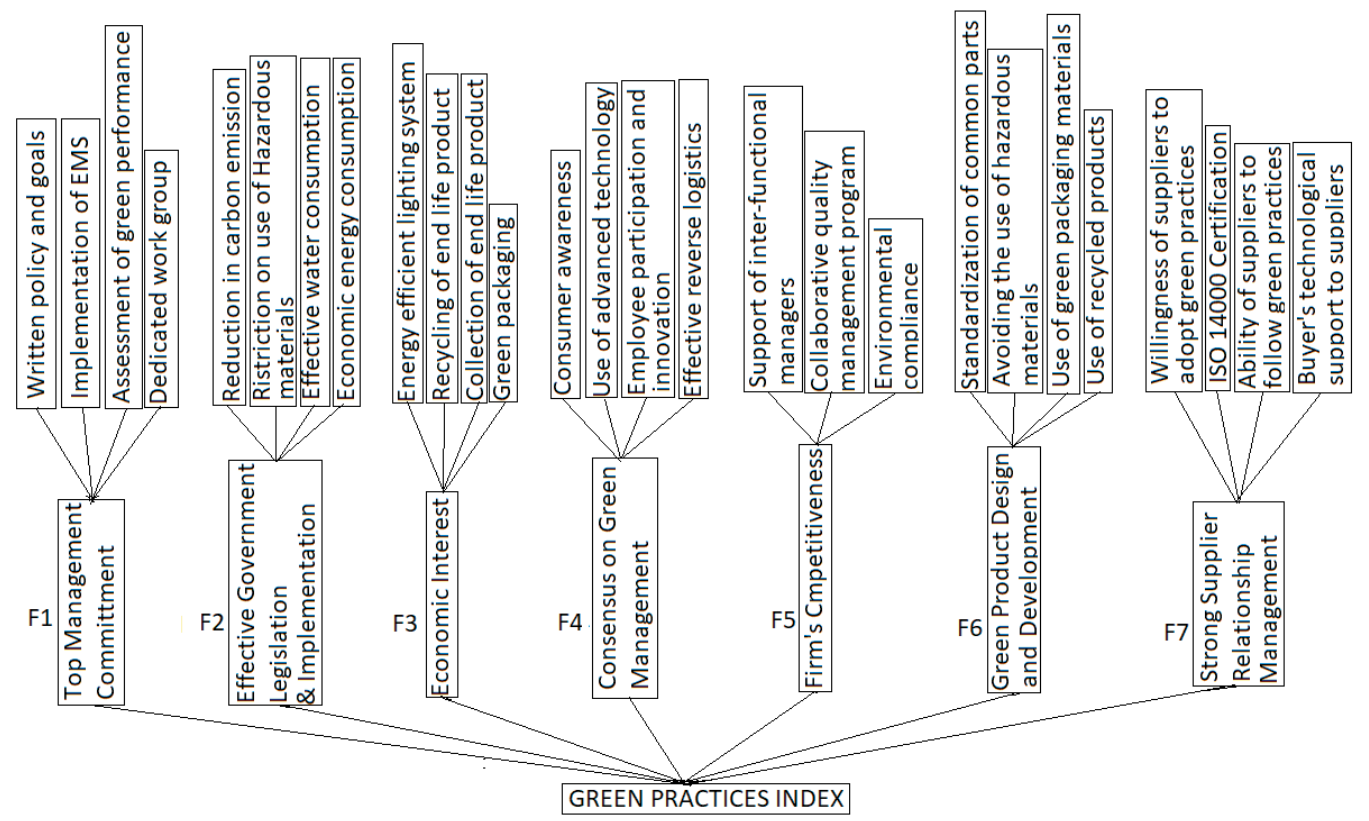

Figure 1. Variables of Green Practices in Small and Medium-Sized Enterprises

Consensus on Green Management: According to Luthra et al. (2011), the customer awareness/demand for the green product may motivate and force the manufacturers towards innovative initiatives for green products. Ravi and Shankar (2005) stated that restriction in information flow across organization hierarchy makes green management implementation infeasible. Digalwar and Metri (2004) stated that innovation and technology enhance corporate culture in which the new ideas and solutions given by the employees are appreciated. It may reduce the resistance to the change from the worker's side. The resistance to change may influence the adaptation of new technology. Thus, there should be a consensus among all the stakeholders for green manufacturing.

Firm 's Competitiveness: It is observed that due to a lack of expertise, the SMEs are not interested in new initiatives. The management of SMEs is facing a lack of technical support, lack of information on new technologies, processes, products, and materials. Therefore, the lack of technical expertise created a major barrier to green practices. For continuous improvement, training for skill and attitude is essential (Hillary, 2004). It helps in implementing green 
practices better. To fulfil the target of green manufacturing employee empowerment and participation is required. Total Quality Management plays a big role in continuous improvement, customer focus, employee empowerment, and innovation.

Green Product Design and Development: Zhou et al. (2008) suggested a framework for evaluating green product design. The product, process, and technology are also identified as three dimensions of green manufacturing (Sarkis and Rasheed, 1995). Many authors recognized green product development as one of the main themes in sustainable supply chain management (Seuring and Muller, 2008; Ashby et al., 2012). Firms are using some tools for analyzing the life cycle, design for the environment, and design for disassembly to reduce the negative impact of products on the environment (Kara et al., 2014; Sarkis, 2001).

Strong supplier relationship: Vendor-managed inventory and strong collaboration with the supplier result in low inventory cost and higher accuracy (Sarkar and Mohapatra, 2006). A good supplier relationship also leads to a competitive advantage for the manufacturers. Hamner (2006) pointed out the importance of supplier's contribution in the production of green products and told that without supplier's support it is very difficult to achieve the goal of environmental management. The sharing of knowledge, information, people's competencies, and skills, are the main purposes of the collaboration, which helps in the efficient running of the supply chain. It is more important to make an environmental collaboration and supplier development, which enhances the capabilities of the supplier to meet the increased challenges within the domain of the firm's practices (Watts and Hahn 1993; De Burgos and Lorenete 2001).

\section{GRAPH THEORY MATRIX APPROACH}

In the Graph Theory matrix approach, the pairwise comparison of the attributes is mapped in both directions For example, if we consider a $0-10$ scale for mapping of factors ' $i$ ' and ' $j$ '. If we show the relative importance of ' $i$ ' over ' $j$ ' using $f_{i j}=3$, the relative importance of ' $j$ ' over ' $i$ ' will be shown as $f_{j i}=7$; i.e. $f_{i j}=10-f_{j i}$. This is the uniqueness of the method. An index is prepared using the digraph mapping of the factors and sub-factors with the help of a permanent matrix.

\section{PERFORMANCE DIGRAPH}

The digraph represents the interrelationships among the factors in terms of nodes and edges. Performance digraph consists of a set of nodes $\mathrm{N}=\left\{n_{i}\right\}, i=1,2,3, \ldots \ldots$ and a set of edges $\mathrm{E}=\left\{f_{i j}\right\}$. A node $n_{i}$ shows the $i^{\text {th }}$ factor and edge $f_{i j}$ shows the measure of interdependence between the factors $i$ and $j$. The total number of nodes, $\mathrm{N}$, is equal to the number of performance factors. The importance of node $i$ over node $j$ is indicated by an edge $f_{i j}$, which is drawn from node $i$ to node $j$. Similarly, the importance of node $j$ over node $i$ is indicated by an edge $f_{j i}$, which is drawn from node $j$ to node $i$. The magnitude of the importance may be different from one factor to another which may be used in the performance matrix. The complexity of the graph increases with increasing the number of nodes and interrelationships and drawing the digraph becomes more difficult; therefore, a performance matrix is used to interpret the relationships (Rao, 2007). A performance matrix consisting of all the factors $\left(F_{i}\right)$ and the relative importance among them $\left(f_{i j}\right)$ is the simplest way to represent the performance digraph. This is an $n \times n$ matrix as shown in Equation (1). It is analogous to the Adjacency matrix in graph theory.

$$
P M=F=\left[\begin{array}{ccc}
F_{i} & f_{i j} & f_{i n} \\
f_{j i} & F_{j} & f_{j n} \\
f_{n i} & f_{n j} & F_{n}
\end{array}\right]
$$

$F_{i}$ is the value of the $i^{\text {th }}$ factor shown by node $n_{i}$. The value of fij shows the relative importance of the $i^{\text {th }}$ factor over 
the $j^{\text {th }}$ factor represented. According to Brualdi and Shader (1990), "the Permanent of a matrix is used to characterize configurations of a system or the structure of a graph and to develop a unique representation that is independent of labelling". This matrix leads to a better appreciation without loss of information in evaluation (Rao and Gandhi, 2002a; Jurkat and Ryser, 1966). The permanent matrix F can be calculated using Equation 2.

$$
\begin{aligned}
& \operatorname{perm} F=\prod_{i=1}^{6} F_{i}+\sum_{i=1}^{5} \sum_{j=i+1}^{6} \sum_{k=1}^{3} \sum_{l=k+1}^{4} \sum_{m=l+1}^{5} \sum_{n=m+1}^{6}\left(f_{i j} f_{j i}\right) F_{k} F_{l} F_{m} F_{n}+\ldots+ \\
& {\left[\begin{array}{l}
\sum_{i=1}^{3} \sum_{j=i+1}^{5} \sum_{k=i+1}^{6} \sum_{l=i+1}^{6} \sum_{m=1}^{6} \sum_{n=m+1}^{6}\left(f_{i j} f_{j k} f_{k l} f_{l i}+f_{i l} f_{l k} f_{k j} f_{j i}\right)\left(f_{m n} f_{n m}\right) \\
+\sum_{i=1}^{1} \sum_{j=i+1}^{5} \sum_{k=j+1}^{6} \sum_{l=1}^{4} \sum_{m=l+1}^{5} \sum_{n=m+1}^{6}\left(f_{i j} f_{j k} f_{k i}+f_{i k} f_{k j} f_{j i}\right)\left(f_{l m} f_{m n} f_{n l}+f_{\mathrm{ln}} f_{n m} f_{m l}\right) \\
+\sum_{i=1}^{1} \sum_{j=i+1}^{6} \sum_{k=i+1}^{3} \sum_{l=i+2}^{6} \sum_{m=k+1}^{5} \sum_{n=k+2}^{6}\left(f_{i j} f_{j i}\right)\left(f_{k l} f_{l k}\right)\left(f_{m n} f_{n m}\right) \\
+\sum_{i=1}^{1} \sum_{j=i+1}^{5} \sum_{k=i+1}^{6} \sum_{l=i+1}^{6} \sum_{m=i+1}^{6} \sum_{n=j+1}^{6}\left(f_{i j} f_{j k} f_{k l} f_{l m} f_{m n} f_{n i}+f_{i n} f_{n m} f_{m l} f_{l k} f_{k j} f_{j i}\right)
\end{array}\right]}
\end{aligned}
$$

Table 2. Values of Performance factors

Exceptionally low influencing

Extremely low influencing

Very low influencing

Below average influencing

Average influencing

Above-average influencing

Moderate influencing

High influencing

Very high influencing

Extremely high influencing 
Green performance Index (GPI): Here, the permanent matrix is represented as Green performance Index (GPI). To calculate the value of GPI, the values of $R_{i}$ and $f_{i j}$ are required. The value of $R_{i}$ is a ranked value judgment on a scale of 0-10 (Rao, 2007) as shown in Table 2 . The value of relative importance of factor $i$ over the factor $j\left(f_{i j}\right)$ is also assigned on the scale $0-10$ as shown in Table 3 . If $f_{i j}$ represents the relative importance of the $i^{\text {th }}$ factor over the $j^{\text {th }}$ factor, then the relative importance of the $j^{\text {th }}$ attribute over the $i^{\text {th }}$ attribute will be $10-f_{i j}$. The permanent functions are evaluated for each factor and finally, GPI is calculated using the permanent functions of all the factors incorporated in the final matrix.

Table 3. Relative importance of performance factors

\begin{tabular}{lcc}
\hline & The relative importance of factors \\
\cline { 2 - 3 } Class description & $i \rightarrow j$ & $j \rightarrow i$ \\
& $f_{i j}$ & $f_{i j}=10-f_{j i}$ \\
\hline Both factors are equally important & 5 & 5 \\
Factor $i$ is slightly more important than factor $j$ & 6 & 4 \\
Factor $i$ is moderately more important than factor $j$ & 7 & 3 \\
Factor $i$ is strongly more important than factor $j$ & 8 & 2 \\
Factor $i$ is extremely more important than factor $j$ & 9 & 1 \\
Factor $i$ is exceptionally more important than factor $j$ & 10 & 0 \\
\hline
\end{tabular}

\section{CASE ILLUSTRATION}

Delhi NCR is a hub of automobile manufacturers and more than $30 \%$ of the total manufacturing of cars in India is produced in Delhi NCR. Two major car manufacturers are Suzuki Motor Limited (Maruti Udyog Limited and Honda motors. A large number of SMEs are involved in the production of auto components. Also, air pollution is a major issue in Delhi NCR. The industry is one of the major contributors to air pollution among the transportation, vehicle, and burning of crop residues (Kumar and Singh, 2020). In this case study, an SME related to auto-component manufacturing has been considered for green performance measurement. The performance is measured in terms of a dimensionless numerical value that is called the green performance index (GPI). GPI can be used to compare the performance of the case company with other auto-component manufacturing companies. The observation is based on the executive's opinion given regarding the implementation of green practices. The factors and sub-factors are rated on a 10-point rating scale with the help of the experts from the industry as shown in Tables 2 and 3. The permanent matrix of the factor $F_{1}$ of four sub-factors can be represented as shown in Equation (3). In the above matrix, R1, R2, R3, and R4 are the four sub-factors of Factor $F_{1}$. The value of diagonal elements is measured on the 10-point rating scale whereas $f_{i j}$ shows the influence of the $i^{\text {th }}$ factor on the $j^{\text {th }}$ factor on the 10-point rating scale e.g. suppose $f_{23}=7$, then $f_{32}$ will be 3. The behavioural digraph can be shown as given in Figure 2. 


$$
\operatorname{Per}\left(\mathrm{F}_{1}\right)=\left[\begin{array}{cccc}
R_{1} & f_{12}^{1} & f_{13}^{1} & f_{14}^{1} \\
f_{21}^{1} & R_{2} & f_{23}^{1} & f_{24}^{1} \\
f_{31}^{1} & f_{32}^{1} & R_{3} & f_{34}^{1} \\
f_{41}^{1} & f_{42}^{1} & f_{43}^{1} & R_{4}
\end{array}\right]
$$

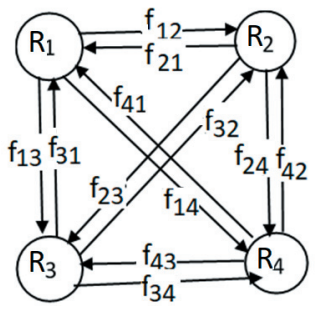

Figure 2. Behavioral digraph

\section{PREPARATION OF GREEN PERFORMANCE INDEX}

$\operatorname{Per}\left(F_{1}\right)=\left[\begin{array}{cccc}4 & 5 & 3 & 2 \\ 5 & 4 & 4 & 3 \\ 7 & 6 & 5 & 4 \\ 8 & 7 & 6 & 5\end{array}\right]=11048$

$\operatorname{Per}\left(F_{2}\right)=\left[\begin{array}{llll}7 & 3 & 6 & 4 \\ 7 & 6 & 6 & 7 \\ 4 & 4 & 4 & 5 \\ 6 & 3 & 5 & 4\end{array}\right]=14491$

$\operatorname{Per}\left(F_{3}\right)=\left[\begin{array}{llll}4 & 4 & 4 & 5 \\ 6 & 4 & 5 & 6 \\ 6 & 5 & 6 & 5 \\ 5 & 4 & 5 & 6\end{array}\right]=14523$

$\operatorname{Per}\left(F_{4}\right)=\left[\begin{array}{llll}4 & 4 & 3 & 3 \\ 6 & 4 & 6 & 5 \\ 7 & 4 & 5 & 4 \\ 7 & 5 & 6 & 3\end{array}\right]=11073$

$\operatorname{Per}\left(F_{5}\right)=\left[\begin{array}{lll}7 & 7 & 4 \\ 3 & 4 & 3 \\ 6 & 7 & 5\end{array}\right]=698$

$\operatorname{Per}\left(F_{6}\right)=\left[\begin{array}{llll}4 & 5 & 6 & 3 \\ 5 & 4 & 5 & 4 \\ 4 & 5 & 3 & 4 \\ 7 & 6 & 6 & 5\end{array}\right]=11630$

$\operatorname{Per}\left(F_{7}\right)=\left[\begin{array}{llll}6 & 4 & 5 & 4 \\ 6 & 4 & 7 & 5 \\ 5 & 3 & 5 & 4 \\ 6 & 5 & 6 & 4\end{array}\right]=13289$

Broadly, 7-factors are shortlisted from the literature review and considering the opinion of the executives. These 
7- factors have many sub-factors, which are used to find the index for all the 7-factors based on the indexing of these 7-factors, the final Green Performance Index is calculated using a Permanent matrix. All these factors are already discussed in detail and Figure 1 shows the concerned subfactors. The maximum value of the permanent of the matrix of size $3 \times 3$ and $4 \times 4$ are calculated as 750 and 15000 respectively considering each value (balanced) in the matrix as 5 on a 10-point rating scale. The rating is based on the preference given to one sub-factor or variable on the 10-point rating scale compared to another. Thus, the permanent of the matrix for all the other factors F1 to F7 are calculated as shown in the matrix F1-F7.

\section{GREEN PERFORMANCE INDEX}

The green performance index depends on the permanent matrices F1-F7. These values are the diagonal elements of the final matrix as shown in Equation (4). The final green index is based on the indices of all the factors from F1 to F7 and their mutual interactions. The final green index can be calculated as shown in Equation (4).

$$
\operatorname{Per}(F)=\left[\begin{array}{lllllll}
F_{1} & f_{12} & f_{13} & f_{14} & f_{15} & f_{16} & f_{17} \\
f_{21} & F_{2} & f_{23} & f_{24} & f_{25} & f_{26} & f_{26} \\
f_{31} & f_{32} & F_{3} & f_{34} & f_{35} & f_{36} & f_{37} \\
f_{41} & f_{42} & f_{43} & F_{4} & f_{45} & f_{46} & f_{47} \\
f_{51} & f_{52} & f_{53} & f_{54} & F_{5} & f_{56} & f_{57} \\
f_{61} & f_{62} & f_{63} & f_{64} & f_{65} & F_{6} & f_{67} \\
f_{71} & f_{72} & f_{73} & f_{74} & f_{75} & f_{76} & F_{7}
\end{array}\right]==\left[\begin{array}{ccccccc}
11048 & 4 & 7 & 6 & 5 & 5 & 4 \\
6 & 14491 & 7 & 7 & 6 & 6 & 7 \\
3 & 3 & 14523 & 4 & 4 & 3 & 5 \\
4 & 3 & 6 & 11073 & 5 & 5 & 4 \\
5 & 4 & 6 & 5 & 698 & 4 & 4 \\
5 & 4 & 7 & 5 & 6 & 11630 & 6 \\
6 & 3 & 5 & 6 & 6 & 4 & 13289
\end{array}\right]=27.77 \times 10^{26}
$$

Maximumvalue of $\operatorname{Per}(\mathrm{F})=58.68 \times 10^{26}$

All the diagonal values of the matrix shown in Equation (6) are taken from the permanents of a matrix of all the factors $\mathrm{F}_{1}$ to $\mathrm{F}_{7}$. The green index calculated as $27.77 \times 10^{26}$ is a type of scale that can be compared with the green index of the other companies. The maximum value of the green index is calculated as $58.68 \times 10^{26}$ considering everything as favourable. Thus, there is an opportunity to improve the green performance of the company. Also, if we analyze the individual factors index with their maximum value, it is observed that the factors F1, F4, and F6 are to be improved.

\section{CONCLUSIONS}

In this study, the factors influencing the green practices in the SMEs have been explored from the past literature, and an index to assess the green practices in SMEs has been produced. The assessment of the implementation of green practices in a small organization needs a qualitative approach. The Permanent matrix of all the seven factors incorporated in this study produces an index which is known as Green Index. The green index may vary from one organization to another due to the subjective judgment of the decision-makers regarding the interactions of the factors and sub-factors. Due to this variation, we can compare the performance of different organizations regarding green production.

Managerial implications: The manager of a company can evaluate the green performance index using a graph-theoretic matrix approach. The uniqueness of this analysis is that these inputs are based on the opinion of the practitioners, which is subjective and can be presented on a 10-point rating scale. This process requires less documentation is required. The manager may produce the green performance index for all the different types of activities at the micro/macro level so that the activity-wise comparison can be made. 


\section{REFERENCES}

Aleisa, E. \& Alshayji, K. 2019. Analysis on Reclamation and Reuse of Wastewater in Kuwait. Journal of Engineering Research, 7(1):1-13.

Alkhidir, T. \& Zailani, S. 2009. Going green in supply chain towards environmental sustainability, Global Journal of Environmental Research, 3(3): 246-251.

Aragón-Correa, J.A., Hurtado-Torres, N., Sharma, S. \& García-Morales, V.J. 2008. Environmental strategy and performance in small firms: A resource-based perspective. Journal of environmental management, 86(1): 88103.

Ashby, A., Leat, M. \& Hudson-Smith, M. 2012. Making connections: a review of supply chain management and sustainability literature. Supply Chain Management: An International Journal, 17(5):497-516.

Brualdi, R.A. \& Shader, B.L. 1990. Matrix factorizations of determinants and permanents. Journal of Combinatorial Theory, 54(1):132-4.

de Burgos, J. \& Lorente, J.J.C. 2001. Environmental performance as an operations objective. International Journal of Operations \& Production Management, 21(12):1553-72.

Diabat, A. \& Govindan, K. 2011. An analysis of the drivers affecting the implementation of green supply chain management. Resources, Conservation and Recycling, 55(6):659-67.

Digalwar, A.K. \& Metri, B.A. 2004. Performance measurement framework for world class manufacturing. International Journal of Applied Management and Technology, 3(2):83-101.

Dubey, R., Gunasekaran, A., Helo, P., Papadopoulos, T., Childe, S.J. \& Sahay, B.S. 2017. Explaining the impact of reconfigurable manufacturing systems on environmental performance: The role of top management and organizational culture. Journal of cleaner production, 141:56-66.

Ghazilla, R.A., Sakundarini, N., Abdul-Rashid, S.H., Ayub, N.S., Olugu, E.U. \& Musa, S.N. 2015. Drivers and barriers analysis for green manufacturing practices in Malaysian SMEs: a preliminary findings. Procedia Cirp, 26(1):658-63.

González-Benito, J. \& González-Benito, Ó. 2006. The role of stakeholder pressure and managerial values in the implementation of environmental logistics practices. International journal of production research, 44(7):135373.

Hamner, B. 2006. Effects of green purchasing strategies on supplier behaviour. In Greening the supply chain, Springer, London, 25-37.

Hillary, R. 2004. Environmental management systems and the smaller enterprise. Journal of cleaner production, 12(6):561-9.

Haque, M. N., Al-Yaqout, A. F., Sreekala, V. \& El-Hawary, M. (2014). Characteristics of recycled aggregate concretes produced in Kuwait: a case study. Journal of Engineering Research, 4(2): 1-17.

Jurkat, W.B. \& Ryser, H.J. 1966. Matrix factorizations of determinants and permanents. Journal of Algebra, 3(1):127.

Kara, S., Ibbotson, S. \& Kayis, B. 2014. Sustainable product development in practice: an international survey. Journal of Manufacturing Technology Management, 25(6):848-72.

Kulkarni, S. 2005. Graph theory and matrix approach for performance evaluation of TQM in Indian industries. The TQM magazine, 17(6): 509-26. 
Kumar, P. \& Singh, R.K. 2020. Selection of sustainable solutions for crop residue burning: an environmental issue in northwestern states of India. Environment, Development and Sustainability, 23(3): 3696-3730.

Luthra, S., Kumar, V., Kumar, S. \& Haleem, A. 2011. Barriers to implement green supply chain management in automobile industry using interpretive structural modeling technique: An Indian perspective. Journal of Industrial Engineering and Management (JIEM), 4(2):231-57.

Molina-Azorín, J.F., Claver-Cortés, E., Pereira-Moliner, J. \& Tarí, J.J. 2009. Environmental practices and firm performance: an empirical analysis in the Spanish hotel industry. Journal of Cleaner Production, 17(5):516-24.

Nasrollahi, M., Razmi, J., \& Ghodsi, R. 2019. A combined fuzzy PCA approach for location optimization and capacity planning in Glycyrrhizae green supply network design. Journal of Engineering Research,7(4):261-275.

Olugu, E.U. \& Wong, K.Y. 2011. Evaluation of green supply chain management practices in the Malaysian automotive industry. International Journal of Services and Operations Management, 9(2):245-58.

Perrini, F. 2006. SMEs and CSR theory: Evidence and implications from an Italian perspective. Journal of business ethics, 67(3):305-16.

Rao, R.V. \& Gandhi, O.P. 2002a. Digraph and matrix methods for the machinability evaluation of work materials. International Journal of Machine Tools and Manufacture, 42(3):321-30.

Rao, R.V. \& Gandhi, O.P. 2002b. Failure cause analysis of machine tools using digraph and matrix methods. International Journal of Machine Tools and Manufacture, 42(4):521-28.

Rao, R.V. 2007. Decision making in the manufacturing environment: using graph theory and fuzzy multiple attribute decision making methods. Springer Science \& Business Media, ISBN978-1-84628-819-7.

Ravi, V. \& Shankar, R. 2005. Analysis of interactions among the barriers of reverse logistics. Technological Forecasting and Social Change, 72(8):1011-29.

Rekik, L. \& Bergeron, F. 2017. Green Practice Motivators and Performance in SMEs: A Qualitative Comparative Analysis. Journal of Small Business Strategy, 27(1):1-8.

Saha, A., Pal, M. \& Pal, T.K. 2007. Selection of programme slots of television channels for giving advertisement: A graph theoretic approach. Information Sciences, 177(12):2480-92.

Sarkar, A. \& Mohapatra, P.K. 2006. Evaluation of supplier capability and performance: A method for supply base reduction. Journal of Purchasing and Supply Management, 12(3):148-63.

Sarkis, J. \& Rasheed, A. 1995. Greening the manufacturing function. BUSINESS HORIZONS-BLOOMINGTON, 38:17.

Sarkis, J. 2001. Manufacturing's role in corporate environmental sustainability - Concerns for the new millennium. International Journal of Operations \& Production Management, 21(5/6): 666-86.

Scupola, A. 2003. The adoption of Internet commerce by SMEs in the south of Italy: An environmental, technological and organizational perspective. Journal of Global Information Technology Management, 6(1):52-71.

Seuring, S. \& Müller, M. 2008. From a literature review to a conceptual framework for sustainable supply chain management. Journal of cleaner production, 16(15):1699-710.

Walley, N. \& Whitehead, B. 1994. It's not easy being green. Reader in Business and the Environment, 36(81):4.

Watts, C.A. \& Hahn, C.K. 1993. Supplier development programs: an empirical analysis. International Journal of Purchasing and Materials Management, 29(1):10-17. 
Wu, G.C., Ding, J.H. \& Chen, P.S. 2012. The effects of GSCM drivers and institutional pressures on GSCM practices in Taiwan's textile and apparel industry. International Journal

Xu, X.D. \& Li, C.X. 2007. Research on immune genetic algorithm for solving the job-shop scheduling problem. The international journal of advanced manufacturing technology, 34(7-8):783-89.

Zailani, S., Govindan, K., Iranmanesh, M., Shaharudin, M.R. \& Chong, Y.S. 2015. Green innovation adoption in automotive supply chain: the Malaysian case. Journal of Cleaner Production, 108:1115-22.

Zailani, S.H., Eltayeb, T.K., Hsu, C.C. \& Tan, K.C. 2012. The impact of external institutional drivers and internal strategy on environmental performance. International Journal of Operations \& Production Management, 32: $721-45$.

Zakuan, N., Saman, M.M. \& Hemdi, A.R. 2012. Critical success factors of green design implementation for Malaysia automotive industry. In Advanced Materials Research, 383: 3395-3402.

Zhou, X., Zhang, Q., Zhang, M. \& Li, X. 2008. Research on evaluation and development of green product design project in manufacturing industry. In2008 4th International Conference on Wireless Communications, Networking and Mobile Computing, 12: 1-5.

Zhu, Q., Sarkis, J. \& Lai, K.H. 2007. Green supply chain management: pressures, practices and performance within the Chinese automobile industry. Journal of cleaner production, 15(11-12):1041-52. 